\title{
Minimizing photooxidation in pasteurized milk by optimizing light transmission properties of green polyethylene films
}

\author{
N. Intawiwat, ${ }^{*}{ }^{1}$ J. P. Wold, ${ }^{*}$ J. Skaret, ${ }^{*}$ E. O. Rukke, $\dagger$ and M. K. Pettersen* \\ *Nofima AS, Osloveien 1, NO-1430 Ås, Norway \\ †Department of Chemistry, Biotechnology and Food Sciences, Norwegian University of Life Sciences, NO-1432 Ås, Norway
}

\begin{abstract}
The effect of different amounts of transmitted green light on photooxidation in pasteurized milk was studied. Five different green films produced with combinations of pigments and additives to minimize exposure to harmful wavelengths with regard to photosensitizers (400-450 and 600-650 nm) were evaluated. In addition, a non-colored transparent film and an orange film were compared with 1 selected green film. Pasteurized milk (3.9\% fat) was packed in an air atmosphere and exposed to light for $14,20,26$, and $32 \mathrm{~h}$ at $4^{\circ} \mathrm{C}$ under the different films. Samples stored in the dark were control samples. The results showed that the mosteffective green film had low overall light transmission, and also almost completely blocked light wavelengths shorter than $450 \mathrm{~nm}$ and wavelengths longer than 600 $\mathrm{nm}$, which prevented photooxidation of riboflavin and chlorophyllic compounds. Chlorophyll degradation was highly correlated with sensory properties (coefficient of determination $=0.80-0.94$ ). To preserve milk quality, total blocking of all visible light would be preferable. If total blocking is not feasible, then light transmission for wavelength below $450 \mathrm{~nm}$ and above $650 \mathrm{~nm}$ should be minimized (e.g., less than 5\%). The newly developed green film can be used as a prototype for protection of dairy products to reduce the degradation of photosensitizers.
\end{abstract}

Key words: milk, photooxidation, packaging, light transmission

\section{INTRODUCTION}

Light is well known for inducing chemical changes in food products and leading to formation of off-flavors and off-odors. Protection against photooxidation can be done by using light-blocking packaging materials. Complete blocking of all visible light by using black or opaque packaging is not always feasible because sometimes a desire exists to see the actual product through

Received January 16, 2013.

Accepted July 27, 2013.

${ }^{1}$ Corresponding author: natthorn_jib@yahoo.com the packaging material. To design a transparent material with optimal protection properties, it is important to know the photochemical properties of the food products. For dairy products, these properties are quite well known, and based on this knowledge it is possible to suggest how transparent films can be optimized for extended shelf life.

Dairy products contain several photosensitizers (riboflavin, porphyrins, and chlorophyllic compounds) that absorb visible light in different wavelength regions (Wold et al., 2005). Riboflavin absorbs wavelengths below $500 \mathrm{~nm}$, which means that it absorbs UV and blue light, whereas chlorophyllic compounds typically absorb light around $420 \mathrm{~nm}$ and above $600 \mathrm{~nm}$. Protoporphyrin IX, present in milk, absorbs strongly around 400 to $420 \mathrm{~nm}$ and have many smaller absorption peaks throughout the visible region.

Wavelengths below $500 \mathrm{~nm}$ have been reported to degrade riboflavin and cause quality deterioration in dairy products (Bekbölet 1990; Bosset et al., 1994; Mortensen et al., 2004). Josephson (1946) reported that wavelengths below $500 \mathrm{~nm}$ degraded riboflavin the most, but that longer visible wavelengths (590-630 nm) induced the strongest formation of sunlight flavor in milk. Recently, Airado-Rodríguez et al. (2011) showed that milk exposed to wavelengths longer than $575 \mathrm{~nm}$ (orange light) induced significantly higher amount of sensory off-flavors than wavelengths shorter than 500 $\mathrm{nm}$ (blue light). This was explained by the photoactivation of tetrapyrroles absorbing in the red region $(>600$ $\mathrm{nm}$ ). The tetrapyrroles typically absorb in the red region as well as in the blue and UV regions. However, milk also contains $\beta$-carotene, which will absorb much of the blue light and thereby reduce photooxidation by this wavelength region. The photosensitizers absorb relatively little between 500 and $600 \mathrm{~nm}$. Thus, excluding the UV and blue light below $500 \mathrm{~nm}$, and the red light longer than about $600 \mathrm{~nm}$ seems to be a feasible approach to avoid the worst photooxidation (Webster et al., 2009, 2011; Intawiwat et al., 2010, 2011; AiradoRodríguez et al., 2011).

In many studies, green light $(450-600 \mathrm{~nm})$ has been shown to give the least-severe effect on photooxidation in dairy products (Hansen et al., 1975; Cladman et al., 
1998; Wold et al., 2005, 2006b; Intawiwat et al., 2010). Green light is least absorbed by photosensitizers in dairy products and green films are, therefore, likely to give longer shelf life compared with blue or red films.

Using a packaging material with light barrier is one alternative to protect against photooxidation. Milk is commonly packed in transparent or translucent white plastic bottles. Coloring of transparent packaging materials can be used to protect and preserve food quality. Brown and green colored materials are used for packing light-sensitive products such as medicine, edible oils, and beer. Transparent packaging materials with different transmission properties, by using color pigments have been applied in the market. Traditionally, colored packaging materials are mostly used for design and to promote sale, and not for specific protection of food products by blocking certain harmful wavelength regions.

Some additives can be used to adjust light transmission properties of materials. Silver $(\mathrm{Ag})$ has a specific absorption peak at $418 \mathrm{~nm}$ (He et al., 2002). Adding $\mathrm{Ag}$ into the material will reduce light transmittance at this wavelength close to chlorophyll absorption. Optical brightener absorbs UV light and it also emits light in the blue/white range of the spectrum, resulting in a whiter and brighter appearance of material (Intawiwat et al., 2012).

The purpose of this study was to investigate the effect of different green polyethylene films on photooxidation in pasteurized milk during light exposure. Because colored packaging materials have different optical properties, they might offer different degrees of protection of the food product. Regarding green films, we also compared the performance of one of the green films with a transparent non-colored film and a transparent orange film. The green film was selected based on providing overall better protection against photooxidation. A trained sensory panel evaluated the level of photooxidation. Fluorescence spectroscopy was used to measure the amount of protoporphyrin IX and chlorophyllic compounds and their degradation during light exposure of the milk.

\section{MATERIALS AND METHODS}

\section{Experimental Design}

Five different polyethylene films and 4 light-exposure times $(14,20,26$, and $32 \mathrm{~h})$ were the parameters used to investigate the effect of different light-transmission properties of green films on photooxidation. There were 2 samples for each combination of films and exposure times. In addition to samples exposed to light, 2 samples were stored in the dark for $32 \mathrm{~h}$ as reference samples. In the study, 42 samples were evaluated [(4 light-exposure times $\times 5$ films $) \times 2$ replicates +2 darkstored samples].

After that, a green film, which tended to give overall good protection with regard to photooxidation, was compared with a non-colored transparent film and an orange film at 4 light-exposure times. A total of 26 samples were evaluated [( 4 light-exposure times $\times 3$ films $) \times 2$ replicates +2 dark-stored samples].

Each milk sample was mixed and poured in 2 white, high-density polyethylene (HDPE) trays. These 2 white trays were put into a black amorphous polyethylene terephthalate $(\mathbf{A}-\mathbf{P E T}) /$ polyethylene $(\mathbf{P E})$ thermoformed tray for the same storage treatment. Of the 2 white trays, one was used for sensory analysis and the other was used for fluorescent spectroscopy. Samples used in this study are shown in Figure 1.

The samples were stored under air atmospheres and exposed to light at $4^{\circ} \mathrm{C}$. The samples were analyzed immediately after light exposure. Sensory analysis was used to measure the formation of off-flavors and offodors, whereas fluorescence spectroscopy was used to study the degradation of photosensitizers. Milk samples were named according to codes in Table 1.

\section{Milk Samples}

Pasteurized bovine milk with $3.9 \%$ fat content packed in gable-top cartons was obtained from a local dairy company (Tine SA, Oslo, Norway). The milk came from the same batch to obtain a fairly homogeneous set of samples. All milk was stored at $4^{\circ} \mathrm{C}$ in darkness before sample preparation.

\section{Packaging Method and Sample Preparation}

Milk from the cartons was blended to obtain a homogenous set of samples. Milk aliquots $(230 \mathrm{~mL})$, measured with sterilized graduated flasks, were placed in white HDPE trays $(5.3 \times 9.2 \times 9.2 \mathrm{~cm}$; Promens AS, Kristiansand, Norway). Two of the HDPE trays were packed in black A-PET/PE thermoformed trays. The A-PET/PE sheets were manufactured by Wipak Oy (Nastola, Finland) and thermoformed by JiHå Plast AB (Karlskoga, Sweden). The thermoformed trays $(14.5 \times 20.5 \times 7.0 \mathrm{~cm})$ were sealed with a top web consisting of $\mathrm{PET} / \mathrm{PE} /$ ethylene vinyl alcohol $(\mathrm{EVOH}) / \mathrm{PE}$ by using a tray-sealing machine (DYNO model 511 VG; Promens AS). OTR of sealed package (A-PET/PE tray and top web) was $0.23 \pm 0.06 \mathrm{~mL}$ of $\mathrm{O}_{2} /$ package per day at $1 \mathrm{~atm}\left(\right.$ at $23^{\circ} \mathrm{C} / 50 \%$ relative humidity). The colored films were placed on the top of sealed packages (Figure 1). Samples were stored in an air atmosphere. 
Table 1. Description of the 7 tested films with different combinations of pigment and additive concentrations

\begin{tabular}{|c|c|c|c|c|c|}
\hline \multirow[b]{2}{*}{ No. } & \multirow[b]{2}{*}{$\begin{array}{l}\text { Film } \\
\text { code }^{1}\end{array}$} & \multicolumn{4}{|c|}{ Pigments and additives (\%) } \\
\hline & & $\begin{array}{c}\text { Microlen } \\
\text { Yellow GR-MC }\end{array}$ & $\begin{array}{c}\text { Eupolen } \\
\text { Green K87-3001 }\end{array}$ & Hitex-OB ${ }^{3}$ & STSS- $10^{4}$ \\
\hline 1 & GY1 & 1.0 & 0.8 & & \\
\hline 2 & GY2 & 3.0 & 1.5 & & \\
\hline 3 & GY1+OB & 1.0 & 0.8 & 0.005 & \\
\hline 4 & GS1 & & 0.8 & & 0.1 \\
\hline 5 & GS2+OB & & 1.5 & 0.01 & 0.2 \\
\hline 6 & $\mathrm{~T}^{5}$ & & & & \\
\hline 7 & $\mathrm{O}^{6}$ & & & & \\
\hline
\end{tabular}

${ }^{1}$ The film code is named according to different pigments and additives used. $\mathrm{G}=$ green pigment; $\mathrm{Y}=$ yellow pigment; $\mathrm{OB}=$ optical brightener; $\mathrm{S}=$ silver additive; $\mathrm{T}=$ transparent non-colored film; $\mathrm{O}=$ transparent orange-colored film.

${ }^{2}$ BASF, Ludwigshafen, Germany.

${ }^{3}$ HPL Additives Ltd., New Delhi, India.

${ }^{4}$ Stabilization Technologies LLC, Charlotte, NC.

${ }^{5}$ Wipak Oy, Nastola, Finland.

${ }^{6}$ Ciba Specialty Inc., Basel, Switzerland.
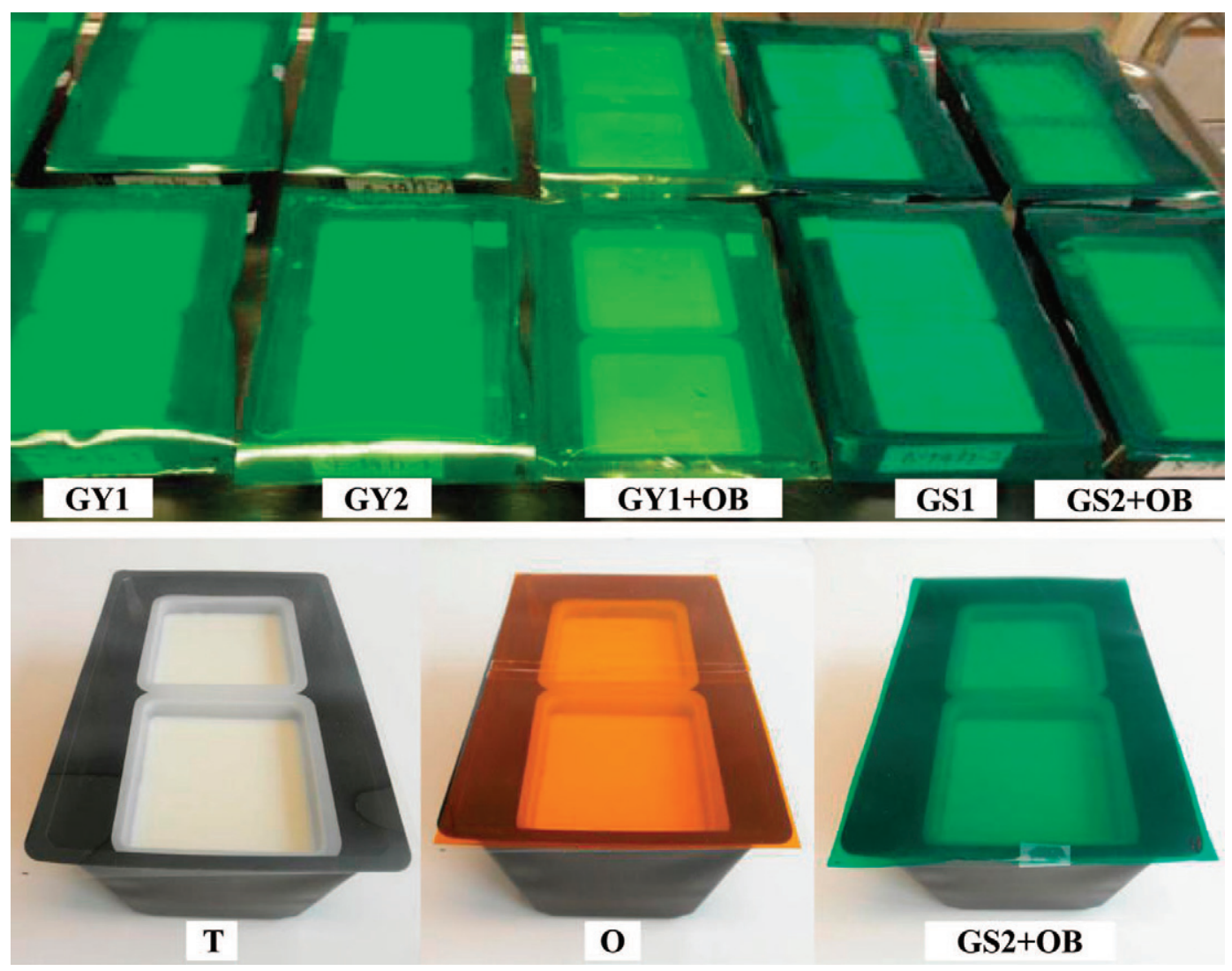

Figure 1. Milk samples used in the study. Milk was packed in 2 white high-density polyethylene (HDPE) trays in an amorphous polyethylene terephthalate/polyethylene (A-PET/PE) black tray. The black trays were sealed and stored in an air atmosphere. Different films were placed on top of the top web on sealed packages. Five different green films with different light-transmission properties are shown in the top half of the picture $(\mathrm{GY}=$ green and yellow pigment; $\mathrm{OB}=$ optical brightener; $\mathrm{GS}=$ green pigment with silver additive); 3 different colored films [green film with a high concentration of green pigment, silver additive, and optical brightener (GS2+OB); non-colored transparent film (T); and orange film $(\mathrm{O})]$ are shown in the bottom half of the picture. 


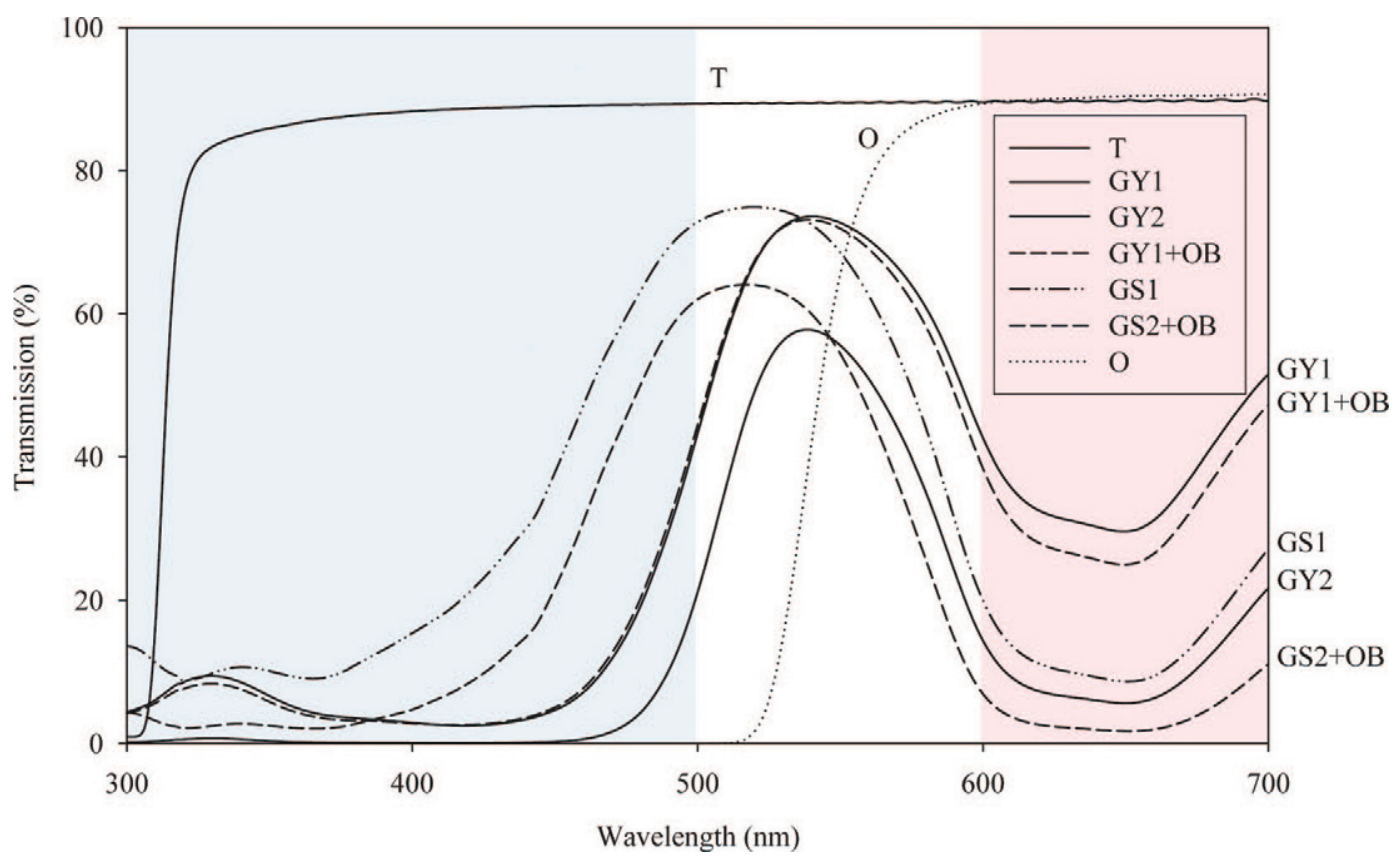

Figure 2. Light transmission (percentage transmitted light per wavelength) in the 300- to 700-nm region of the 7 different films used in this experiment (see Table 1). GY1 = film with a low concentration of green and yellow pigment; GY1+OB = GY1 film with optical brightener; GY2 = film with a high concentration of green and yellow pigment; GS1 = film with a low concentration of green pigment and silver additive; $\mathrm{GS} 2+\mathrm{OB}=$ film with a high concentration of green pigment, silver additive, and optical brightener; $\mathrm{T}=$ non-colored transparent film; $\mathrm{O}=$ orange film. The absorption of riboflavin and chlorophyll are located in wavelengths between 300 and 500 nm, whereas chlorophyll is located in wavelengths 600 to $700 \mathrm{~nm}$. Color version available in the online PDF.

\section{Packaging Material}

Seven different films were used in this study, as shown in Table 1. Further information about producing the films is available from Intawiwat et al. (2012). Five transparent green low-density polyethylene (LDPE) blown films with different light transmission profiles were produced by Norner AS (Stathelle, Norway). The films were produced with different concentrations and combinations of pigments, silver additive, and optical brightener. Additives and pigments were selected according to their specific absorption to block the desired wavelength: 400 to 450 and 600 to $660 \mathrm{~nm}$. Commercialgrade LDPE (FT5236; Borealis AG, Vienna, Austria) was used as a polymer base. In addition, orange and transparent non-colored films were evaluated. The transparent film (PET/PE/EVOH/PE) was obtained from Wipak Oy. Orange transparent film based on PET was manufactured by Ciba Specialty Inc. (Basel, Switzerland). These 2 films were compared with one of the green films that gave overall good protective properties with regard to photooxidation.

Light transmission properties of these films are shown in Figure 2. The spectral regions of the films were defined by where the transmission was above $10 \%$.
The total light transmittance through each film was calculated by integrating the area under the light transmission spectra from 300 to $700 \mathrm{~nm}$ (Figure 3).

\section{Light Exposure}

The milk samples were placed on the floor in a refrigerated room $\left(3-4^{\circ} \mathrm{C}\right)$ under 2 broadband $575-\mathrm{W}$ metal halide lamps (Osram HMI 575W/SE; Osram GmbH, Munich, Germany). The light intensity was measured by a calibrated spectrometer (Apogee spectroradiometer; Apogee Instruments Inc., Logan, UT) for the integrated 300- to 700-nm wavelength region, as described by Wold et al. (2005).

The intensity of light was measured on top of the color films and adjusted to $2.0 \pm 0.1 \mathrm{~W} / \mathrm{m}^{2}$ for every sample by the use of gray filters. The intensity of light was measured in the cooling room in which the experiment was performed.

All samples were placed on the floor at the same time. Samples exposed to light for 26, 20, $14 \mathrm{~h}$ were covered by aluminum foil to protect against light. The aluminum foil was removed after light exposure every $6 \mathrm{~h}$ until the end of the final $14 \mathrm{~h}$. Thus, light exposure was finished at the same time for all samples. 


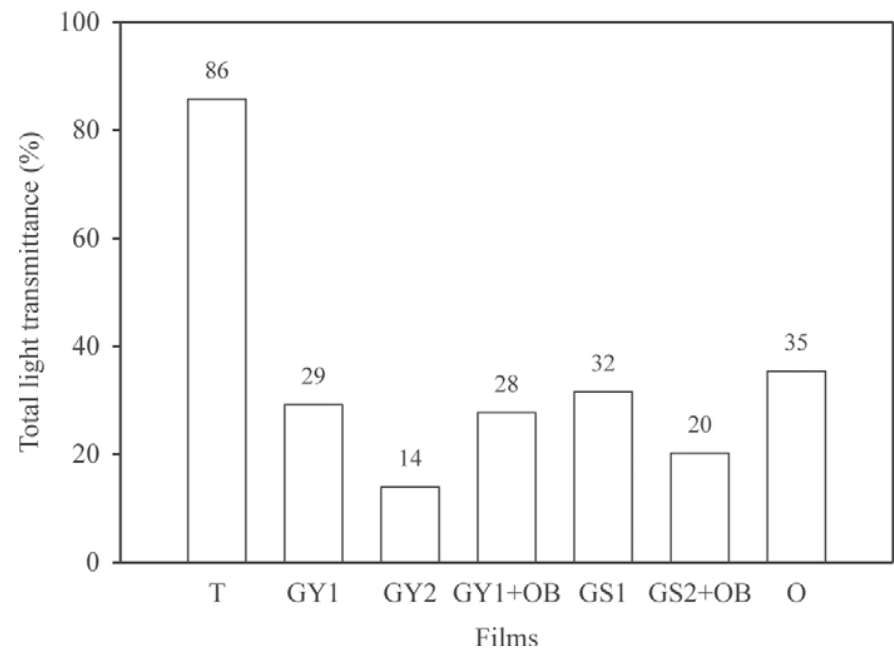

Figure 3. Total transmitted light (\%) of the 7 different films used in the experiment. The intensity was calculated by integrating the area under the light transmission spectra curve between 300 and 700 $\mathrm{nm}$ for each film. GY1 = film with a low concentration of green and yellow pigment; GY1+OB = GY1 film with optical brightener; GY2 = film with a high concentration of green and yellow pigment; GS1 $=$ film with a low concentration of green pigment and silver additive; $\mathrm{GS} 2+\mathrm{OB}=$ film with a high concentration of green pigment, silver additive, and optical brightener; $\mathrm{T}=$ non-colored transparent film; $\mathrm{O}$ = orange film.

\section{Sensory Analysis}

Pasteurized milk was evaluated by a trained sensory panel at Nofima AS (Ås, Norway) using a modified quantitative method as described by the International Organization for Standardization (ISO, 1985) standard 6564. The sensory panel consisted of 10 assessors. The details of the sensory analysis methodology are presented in Intawiwat et al. (2010). Prior to the analysis, the panel was trained to agree on the definition and intensities of each of the attributes. The training session included 2 different milk samples with varying sensory properties [one was a dark stored sample and another was light-exposed for $32 \mathrm{~h}$ under a film with low concentration of green and yellow pigment (GY1) in the first experiment and under transparent non-colored film in the second experiment].

Six attributes were selected: freshness, rancid, and sunlight odors and flavors. Freshness refers to odor and flavor of fresh milk and a high intensity indicates freshness. Sunlight odor and flavor are related to oxidation of proteins, and rancid odor and flavor include all odors and flavors associated with rancidity (grass, hay, candle, and paint) as described in ISO (2009; standard 22935-2). Samples were stirred to ensure homogeneity before they were poured into the plastic cups. Samples were served at room temperature $\left(20^{\circ} \mathrm{C}\right)$ in plastic cups (tested to be free from interfering odors and flavors).
The different samples were served where the serving order was randomized with respect to sample, assessor, and replicate. Unsalted crackers and lukewarm water were available for rinsing the palate between samples. Samples were divided to 5 sessions (5-6 samples per session). Each session had rest periods of $15 \mathrm{~min}$ between sessions.

Intensity of odors and flavors were evaluated and graded on a continuous nonstructured scale, ranging from the lowest intensity of each attribute (value 1.0) to the highest intensity (value 9.0). The samples were evaluated in all attributes by each assessor. The sensory intensities for each sample were obtained by averaging the individual intensities from the 10 assessors. The evaluation was carried out and data recorded by a computerized system (CSA, Compusense, version 4.6; Compusense Inc., Guelph, ON, Canada).

In the study of the 5 different green films, 42 samples were evaluated. The sensory measurements therefore had to be carried out over $2 \mathrm{~d}$ due to capacity limitation. Samples were randomized over $2 \mathrm{~d}$ to avoid block effects. To study the effect of the non-colored transparent, orange, and green films, 26 samples were evaluated. Sensory testing was performed within $1 \mathrm{~d}$.

\section{Fluorescence Spectroscopy}

Milk samples were stirred to ensure homogeneity. Then, milk $(20 \mathrm{~mL})$ from each sample was poured into sample cuvettes that exposed a flat, circular surface with a diameter of $5 \mathrm{~cm}$ for the measurements. Fluorescence emission spectra were measured on the milk surface. The front face fluorescence set up is described in detail by Wold et al. (2005). The fluorescence emission spectra were measured in the range 500 to 720 $\mathrm{nm}$ for excitation at $410 \mathrm{~nm}$ (Oriel 59285 filter; Oriel Corp., Stratford, CT) using cut-off filters at $475 \mathrm{~nm}$ (Melles Griot 03FCG065; Melles Griot Inc., Rochester, $\mathrm{NY}$ ). Excitation at $410 \mathrm{~nm}$ was used to maximize fluorescence for the tetrapyrroles (Wold et al. 2002, 2005). Moreover, excitation at $410 \mathrm{~nm}$ can also be used to measure riboflavin.

The spectra were collected by a spectrograph (Acton SP-150; Acton Research Corp., Acton, MA) connected to a charge-coupled device camera (Roper Scientific NTE/CCD-1340/400-EMB; Roper Scientific, Trenton, $\mathrm{NJ}$ ). The exposure time was $0.5 \mathrm{~s}$ for all measurements. The temperature of the samples was $4^{\circ} \mathrm{C}$. Samples were measured twice. Samples were rotated $90^{\circ}$ between each measurement to average out possible nonhomogenous field of illumination. The spectrograph and detector were controlled by the software WinSpec (version 1.4.3.4; Roper Scientific). 
To improve interpretation of spectral response for protoporphyrin IX and chlorophyll compounds, the large background signal from riboflavin was removed from the fluorescence emission spectra. This was performed by polynomial fitting, an iterative routine originally introduced to remove background fluorescence from Raman spectra (Lieber and Mahadevan-Jansen, 2003). The final polynomial fit is subtracted from the original spectrum. In the present study, a polynomial degree of 5 was chosen and an iteration number of 50 was used for the fitting procedure. The correction was only applied to the part of spectrum between 575 and $750 \mathrm{~nm}$. The procedure was written in Matlab code (The MathWorks Inc., Natick, MA).

\section{Data Analysis}

Partial least-squares (PLS) regression was used to find correlations between fluorescence spectra and sensory assessed attributes. Full cross-validation was used to determine the optimal number of PLS factors. The PLS regression was carried out by using The Unscrambler version 7.5 software (Camo Software AS, Oslo, Norway).

Significance testing of the sensory analysis was carried out within each treatment using a general linear model (GLM) using SAS (version 9.1.3; SAS Institute Inc., Cary, NC) to establish significant differences, followed by the Tukey honestly significantly different (HSD) test.

\section{RESULTS AND DISCUSSION}

\section{Sensory Analysis}

The effect of the different green films is shown by average sensory scores for freshness, and sunlight and rancid flavors (Figure 4). Large variations in flavor scores were observed compared with odor scores. This might be because the taste of samples gave more intense perception than smell. Thus, the flavors are used for presenting the sensory results.

A significant difference in freshness flavor at $14 \mathrm{~h}$ was found only between samples stored in the dark and sample covered with film with low concentrations of green and yellow pigment (GY1; Figure 4A). At 20 $\mathrm{h}$, films with low concentrations of green and yellow pigment with (GY1+OB) and without (GY1) optical brightener, and low concentration of green pigment with silver additive (GS1) resulted in significantly lower freshness scores than the dark storage sample. At $26 \mathrm{~h}$, all exposed samples were significantly different from the sample stored in the dark. However, after light exposure for $32 \mathrm{~h}$, the sample with a high concentration of green and yellow pigment (GY2) was again not significantly different from the sample stored in the dark.

Figure 4B shows the results for sunlight flavor. Milk stored under film GY1, GY1+OB, and GS1 had significantly higher levels of sunlight flavor compared with the reference at light exposure for 20 up to $32 \mathrm{~h}$. These films also had the highest percentage of transmitted light, with around 30\% (Figure 3); next was the film GS2+OB at $20 \%$ and last the film GY2 at $14 \%$ transmitted light. These results show that light transmittance in green wavelength regions of $30 \%$ were enough to initiate the photoreaction in milk samples at $20 \mathrm{~h}$ of light-exposure time. Furthermore, although film GY1 transmitted the same amount of total light as GY1+OB and GS1 (Figure 3), the light transmission profile was different. Film GS1 transmitted more light in the violet and blue wavelength regions $(300-500$ $\mathrm{nm}$ ) than film GY1 and GY1+OB (Figure 2). On the other hand, film GY1 transmitted light in red regions (600-700 nm) 3 times higher than film GS1. A trend existed that sample GY1 had higher off-flavor scores than sample GS1 at light exposure for 20 up to $32 \mathrm{~h}$ (Figure $4 \mathrm{~B}$ and $4 \mathrm{C}$ ), which suggests that orange and red light causes more photooxidation than blue light. This corresponds with findings by Airado-Rodríguez et al. (2011) and Intawiwat et al. (2011).

A significant difference in rancid flavor between dark storage and light-exposed samples was only found in sample GY1 from 20 to $32 \mathrm{~h}$ (Figure 4C). No significant difference was found between samples stored under different green films. Overall, samples GY2 and GS2+OB had less off-flavor compared with the other samples after $20 \mathrm{~h}$ of light exposure. Meanwhile, sample GY1 had significantly higher sunlight flavor at $14 \mathrm{~h}$ and rancid flavor at $20 \mathrm{~h}$ compared with the sample stored in the dark. The reason that film GY2 may give better protection against off-flavors was because the total transmitted light of this film was the lowest (Figure 3). Film GS2+OB transmitted light below $5 \%$ in both blue and red regions (Figure 2). These results might indicate that reducing transmitted light in both wavelength regions (blue and red light regions) provides good protection against light-induced oxidation in milk.

In the follow-up experiment, the results for non-colored transparent, orange, and green films is presented by average sensory scores for 3 attributes: freshness, and sunlight and rancid flavors (Figure 5). The green film GS2+OB was selected for comparison with a noncolored transparent $(\mathrm{T})$ film and an orange $(\mathrm{O})$ film. The reason we selected film GS2+OB was that this film showed better protection against off-flavors compared with the other green films. Furthermore, this film had the lowest light transmission below $5 \%$ in both blue and red wavelength regions, which is more interesting 

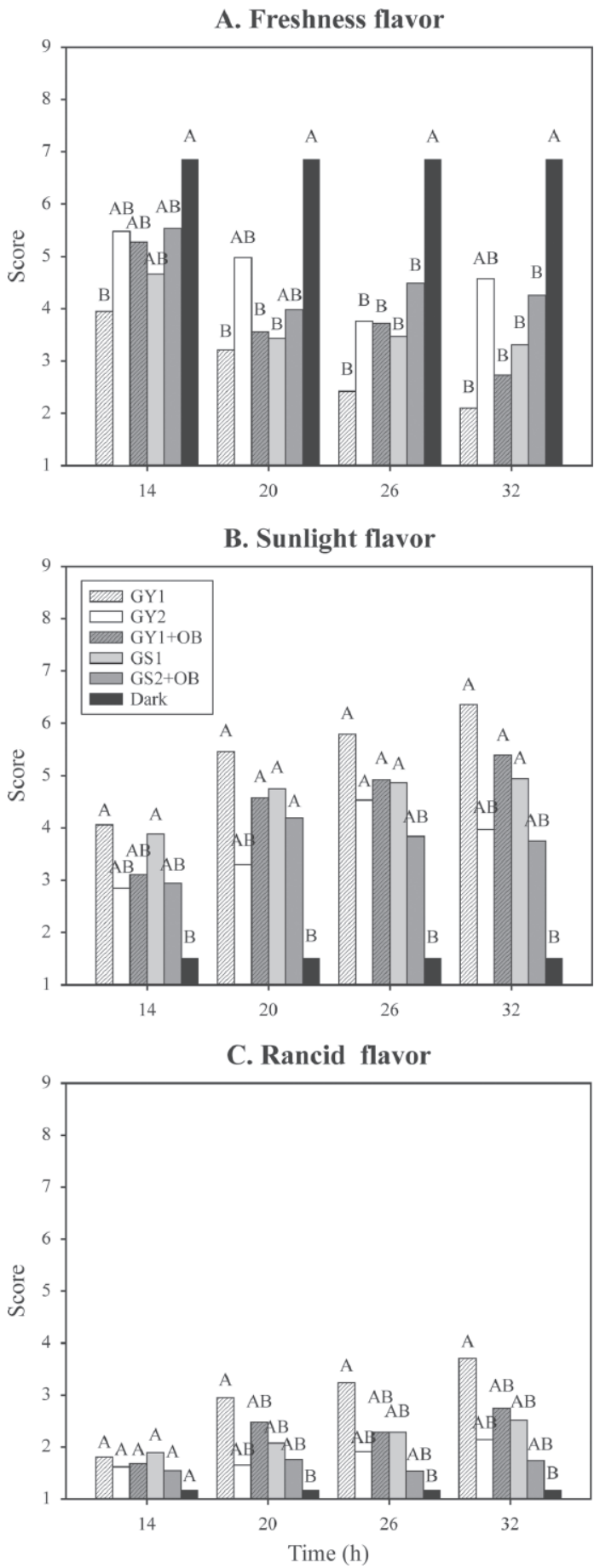

Figure 4. Mean sensory scores for (A) freshness flavor, (B) sunlight flavor, and (C) rancid flavor of milk stored under 5 different green films exposed to light at different exposure times, in addition to a sample stored in the dark as a reference sample. Only samples within the same exposure time were compared. Samples marked with the same letter (A and B letters at top of bars) are not significantly different $(P>0.05)$. GY1 $=$ film with a low concentration of green and yellow pigment; GY1+OB = GY1 film with optical brightener; GY2 = film with a high concentration of green and yellow pigment; GS1 = film with a low concentration of green pigment and silver additive; $\mathrm{GS} 2+\mathrm{OB}=$ film with a high concentration of green pigment, silver additive, and optical brightener. for the chlorophyll study. A significant difference was found between samples under non-colored transparent film and GS2+OB after light exposure at 14 to $26 \mathrm{~h}$ (Figure 5A). Additionally, at $26 \mathrm{~h}$ of light exposure, a significant difference was also found between samples under orange film and GS2+OB. Sample GS2+OB had significantly less sunlight flavor compared with transparent film at 14 to $26 \mathrm{~h}$ of exposure (Figure 5B). A significant difference between sample GS2+OB and orange film was found only at $26 \mathrm{~h}$ of exposure. However, no differences were observed in freshness flavor and sunlight flavor between the samples at $32 \mathrm{~h}$. Samples GS2+OB had significantly lower intensity of rancid flavor than transparent and orange films at 20 and $26 \mathrm{~h}$ (Figure 5C). At $32 \mathrm{~h}$, the only significant difference was between GS2+OB and the transparent material. The newly developed film GS2+OB gave significantly less off-flavor at $26 \mathrm{~h}$ of exposure compared with samples stored under transparent and orange films. Similar results have previously been presented (Intawiwat et al., 2010). No significant differences in off-flavors were found between exposure to light under transparent and orange films, although the transparent film had a much higher total light transmittance (86\%) compared with the orange film (35\%; Figure 3). Airado-Rodríguez et al. (2011) showed that in milk samples exposed to orange light of only half of the total intensity compared with white light, the formation of off-favors was at the same level for the 2 exposure conditions.

\section{Fluorescence Spectroscopy}

Fluorescence spectroscopy has been used to monitor the amount of photosensitizer compounds and their degradation after light exposure in dairy products (Wold et al., 2005). The photooxidative processes in the product start when the photosensitizers are photobleached. The decrease in fluorescence intensity of the sensitizers can, therefore, be used as a marker for photooxidation measured by sensory analysis (Wold et al., 2005). A detailed study of how photosensitizers are degraded under different exposure conditions can be used to understand and interpret how the light affects the products.

The degradation of riboflavin is not presented in this study because the main interest was to investigate the effect on chlorophyllic compounds. In addition, all green films transmitted light mostly in green wavelength regions and less in blue regions; thus, little effect was observed on the degradation of riboflavin.

Webster et al. (2009) suggested that riboflavin absorbs at $570 \mathrm{~nm}$ and this should be taken in to account when considering photooxidation in milk. However, we have not found evidence for this in the literature. Sattar 
A. Freshness flavor

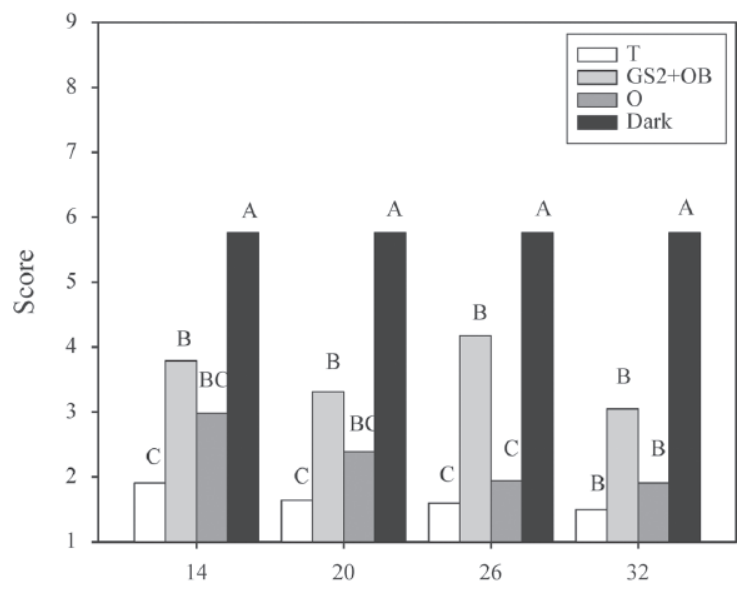

B. Sunlight flavor

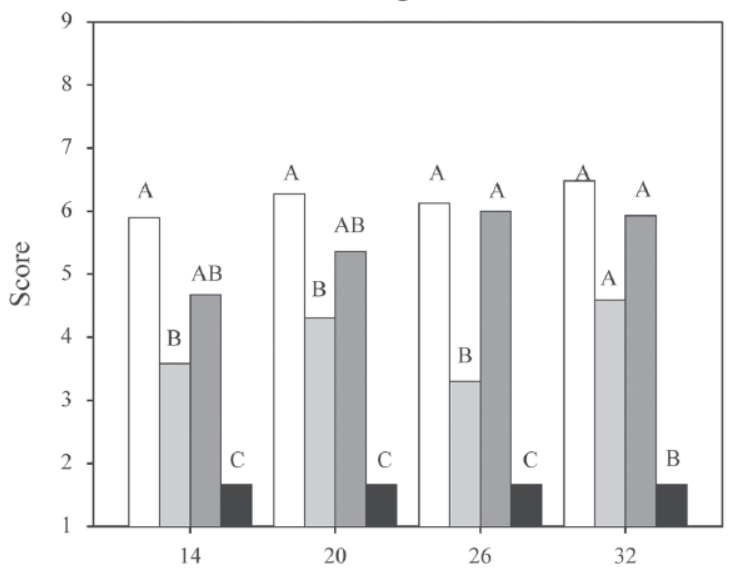

C. Rancid flavor

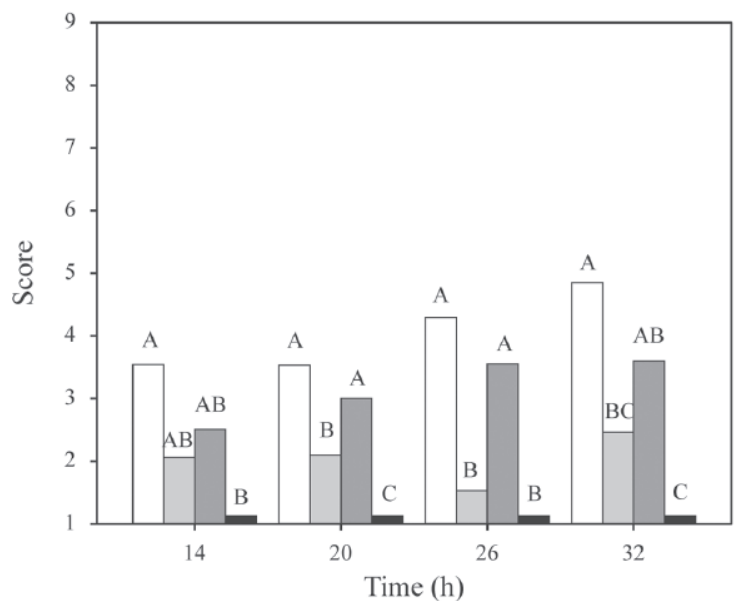

Figure 5. Mean sensory scores for (A) freshness flavor, (B) sunlight flavor, and (C) rancid flavor of milk stored under 3 different colored films: film with a high concentration of green pigment, silver additive and optical brightener (GS2+OB); non-colored transparent film $(\mathrm{T})$; and orange film $(\mathrm{O})$. The samples were exposed to light at different exposure times. In addition, a sample was stored in the dark as a reference sample. Only samples within the same exposure time were compared. Samples marked with the same letter (A-C letters at top of bars) are not significantly difference $(P>0.05)$. et al. (1977) showed that a wavelength of $570 \mathrm{~nm}$ did not degrade riboflavin. Airado-Rodríguez et al. (2011) published absorption spectra of riboflavin showing that no absorption existed at $570 \mathrm{~nm}$.

The fluorescence emission spectra of protoporphyrin IX and chlorophyll are presented for samples exposed to light for $32 \mathrm{~h}$ (Figure 6). The peak at 635 is generated by protoporphyrin IX (Juzenas et al., 2001; Wold et al., 2006a). The broad peak at 661 to 680 originates from chlorophyll residues (Merzlyak et al., 1996) and has previously been observed in pasteurized milk (Intawiwat et al., 2010; Airado-Rodríguez et al., 2011).

The degradation of protoporphyrin IX and chlorophyllic compounds is closely correlated with the duration of light exposure, whereas dark storage prevented photobleaching of these compounds. Comparing samples exposed to light, sample GS2+OB had the least degradation of chlorophyllic compounds, followed by GY2, GS1, and GY1 GY1+OB.

According to Figure 6, it seems that film GS2+OB gave better protection of chlorophyll than GY1, although film GS2+OB transmitted more light than film GY1 in the 400- to 500-nm region (Figure 2). However, the film GS2+OB had the lowest light transmittance in the 600- to 700-nm region, whereas film GY1 had the highest light transmittance. The results indicate that exposure to longer wavelengths (above $600 \mathrm{~nm}$ ) was more harmful to the chlorophyll compounds than the shorter wavelengths.

Airado-Rodríguez et al. (2011) suggested 2 reasons for why chlorophyll is more degraded by longer wavelengths (red light) than shorter wavelengths (blue light). First of all, the longer wavelengths penetrate deeper into the product than the shorter wavelengths. Intawiwat et al. (2011) recently reported that red light penetrated deeper into cheese and consequently degraded protoporphyrin and chlorophyll compounds in a larger volume than did blue light. Milk is a highly light-scattering medium. Blue light is scattered more than red light (Qin and $\mathrm{Lu}, 2007$ ) and this affects the amount of light that interacts with the molecules in the milk. Second, much of the blue light is absorbed by $\beta$-carotene and riboflavin, so a smaller part of the light is absorbed by tetrapyrroles. In the red light regions, however, tetrapyrroles are the main absorbing compounds.

The estimated relative concentrations of chlorophyll and protoporphyrin IX in milk stored under different films and different exposure times are presented in Figure 7 . These relative concentrations are obtained from the fluorescence emission peaks of chlorophyll at 676 $\mathrm{nm}$ and protoporphyrin IX at $635 \mathrm{~nm}$. As expected, the concentration of chlorophyll was stable in samples stored in the dark, whereas it decreased in samples 


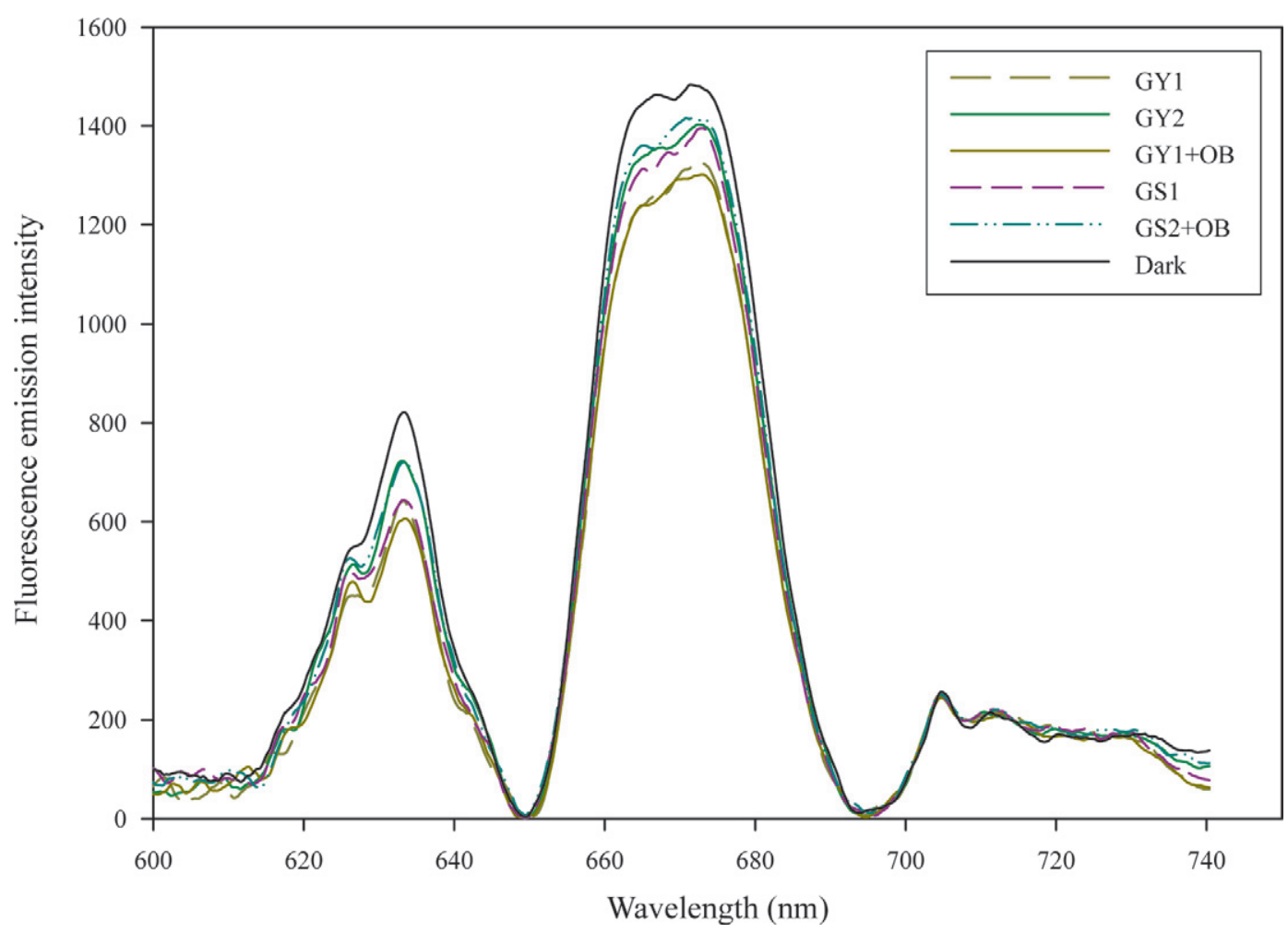

Figure 6. The baseline-corrected fluorescence emission spectra [excitation wavelength $(\lambda \mathrm{ex})=410 \mathrm{~nm}$ ] obtained from milk stored under 5 different green films exposed to light for $32 \mathrm{~h}$. GY1 = film with a low concentration of green and yellow pigment; GY1+OB = GY1 film with optical brightener; GY2 = film with a high concentration of green and yellow pigment; GS1 = film with a low concentration of green pigment and silver additive; GS2+OB = film with a high concentration of green pigment, silver additive, and optical brightener. The reference sample was milk stored in the dark.

exposed to light (Figure 7A). Chlorophyll compounds were less degraded in samples GY2 and GS2+OB, and the most degraded in sample GY1+OB. Similar results were observed for protoporphyrin IX (Figure 7B). This could be expected, as film GY1+OB transmitted $25 \%$ light, whereas films GS2+OB and GY2 transmitted less than 5 and $10 \%$ light, respectively, at 600 to $650 \mathrm{~nm}$ (Figure 2). The results show that an increase in light transmittance of 15 to $20 \%$ in red regions was enough to degrade chlorophyll.

The fluorescence emission spectra of pasteurized milk exposed to white, orange, and green light for $32 \mathrm{~h}$ are shown in Figure 8. Chlorophyll in samples stored under orange film was the most degraded, less under noncolored transparent film, and the least under GS2+OB film. These results correspond very well to the sensory results, where sample GS2+OB had less sensory offflavors and off-odors than the other samples (except for the dark-stored control).

The degradation of protoporphyrin IX and chlorophyll compounds showed high correlation with the sensory properties $\left(\mathrm{R}^{2}=0.80-0.94\right)$. The correlations between the peak of protoporphyrin and chlorophyll compound in the 620- to $750-\mathrm{nm}$ region and sunlight and rancid flavors were 0.85 and 0.90 . Similar results have been reported for milk (Intawiwat et al., 2010; Airado-Rodríguez et al., 2011), butter (Wold et al., 2006a), and cheese (Intawiwat et al., 2011).

\section{CONCLUSIONS}

Effects of different light transmission properties of green polyethylene films on photooxidation in pasteurized milk were studied. Blocking or minimizing transmission of wavelengths below $450 \mathrm{~nm}$ and above 600 $\mathrm{nm}$ reduced photooxidation in milk because the main absorption bands of tetrapyrroles and riboflavin was protected. Apparently, chlorophyllic compounds and protoporphyrin IX in milk are responsible for photooxidation induced by the longer wavelengths above 600 $\mathrm{nm}$. The degradation of these compounds measured by fluorescence spectroscopy was a good indicator for sensory off-flavors. A designed green polyethylene film was able to reduce photooxidation of pasteurized milk compared with a non-colored transparent film and an orange film. Blocking specific harmful wavelength 
$\mathbf{A}$

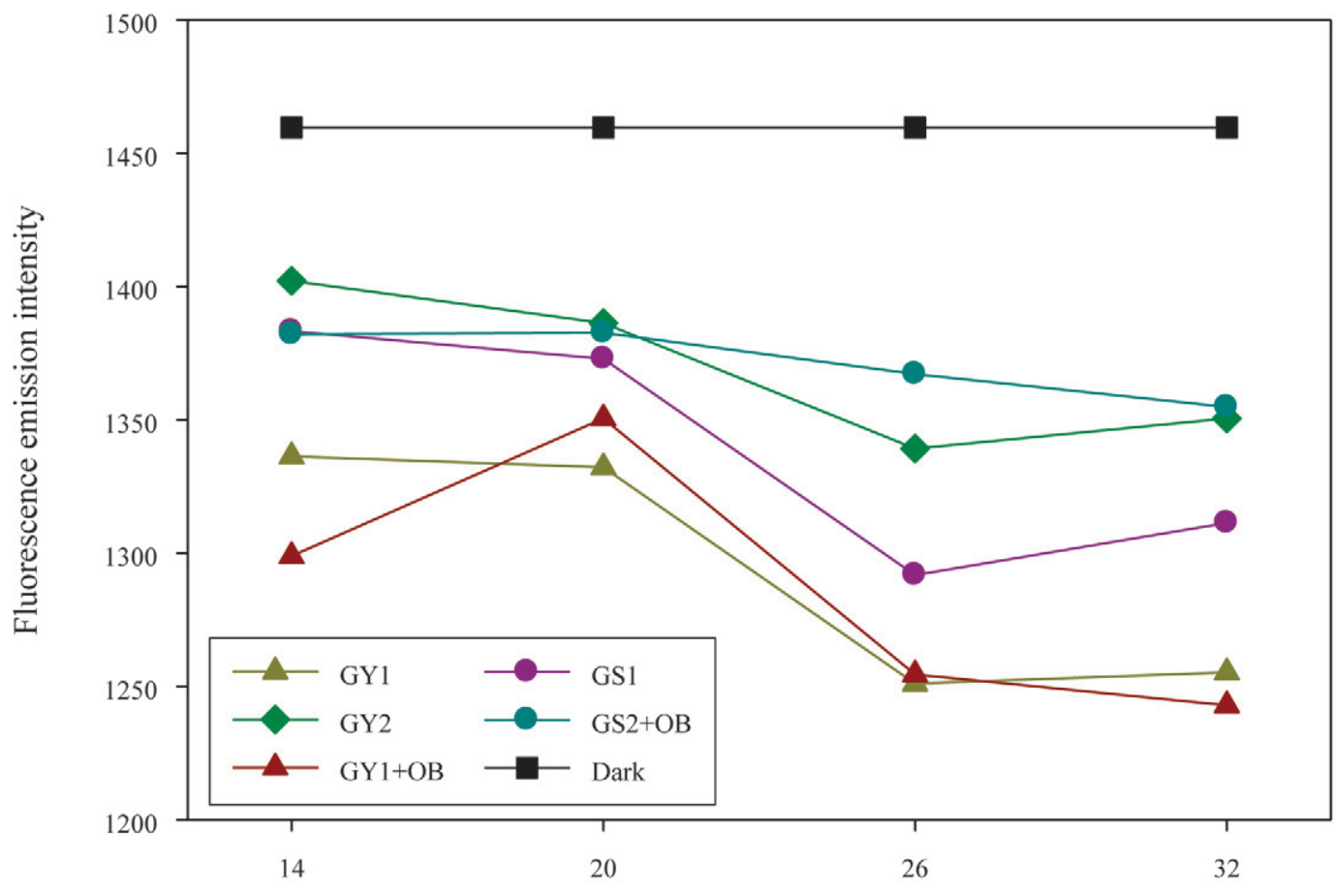

B

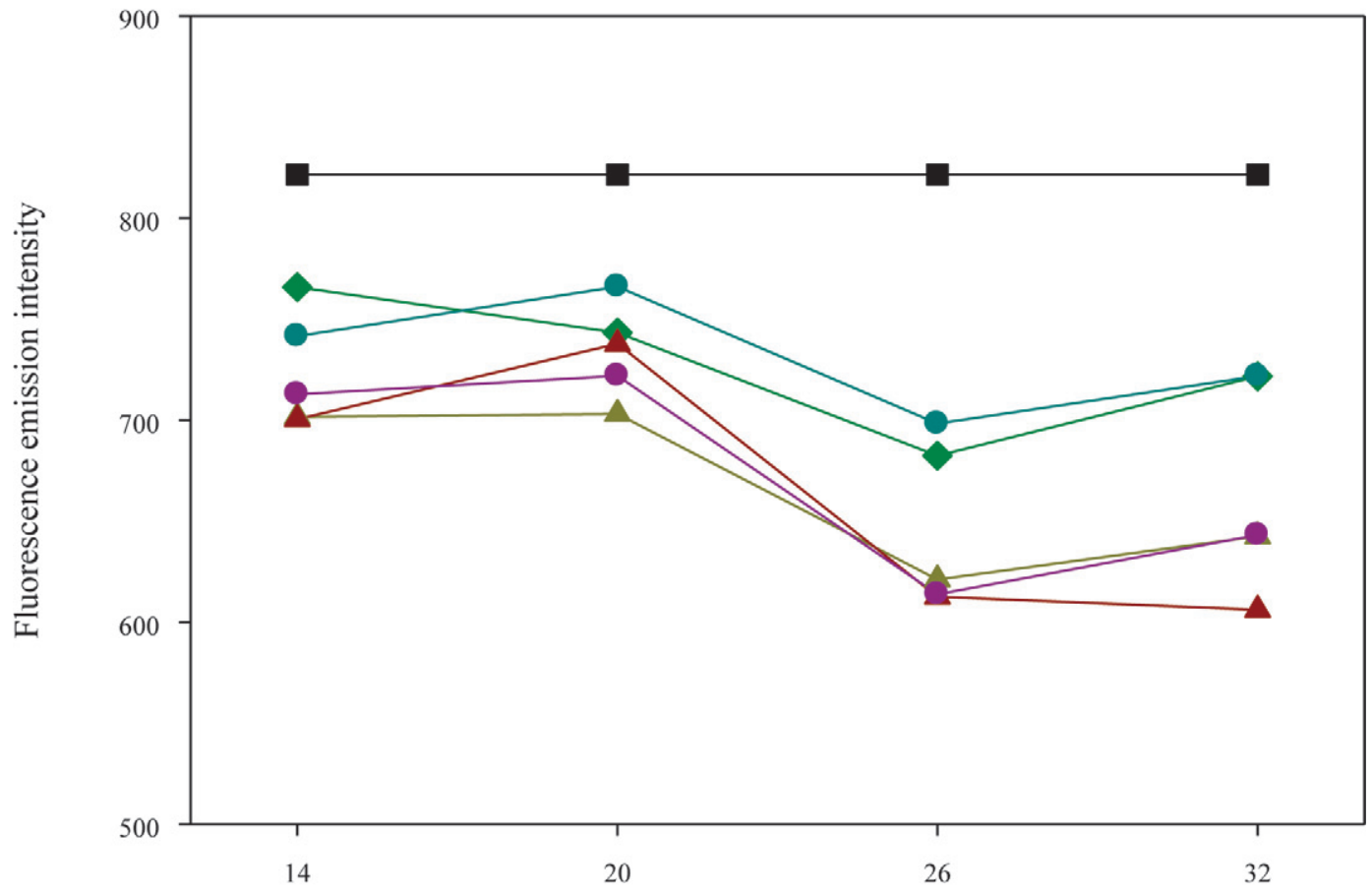

Time (h)

Figure 7. The relative concentration of (A) chlorophyll at $676 \mathrm{~nm}$ and (B) protoporphyrin IX at $643 \mathrm{~nm}$ in milk stored under 5 different green films with different light-exposure times. GY1 = film with a low concentration of green and yellow pigment; GY1+OB = GY1 film with optical brightener; GY2 = film with a high concentration of green and yellow pigment; GS1 = film with a low concentration of green pigment and silver additive; GS2+OB = film with a high concentration of green pigment, silver additive, and optical brightener. The reference sample was milk stored in the dark. Color version available in the online PDF. 


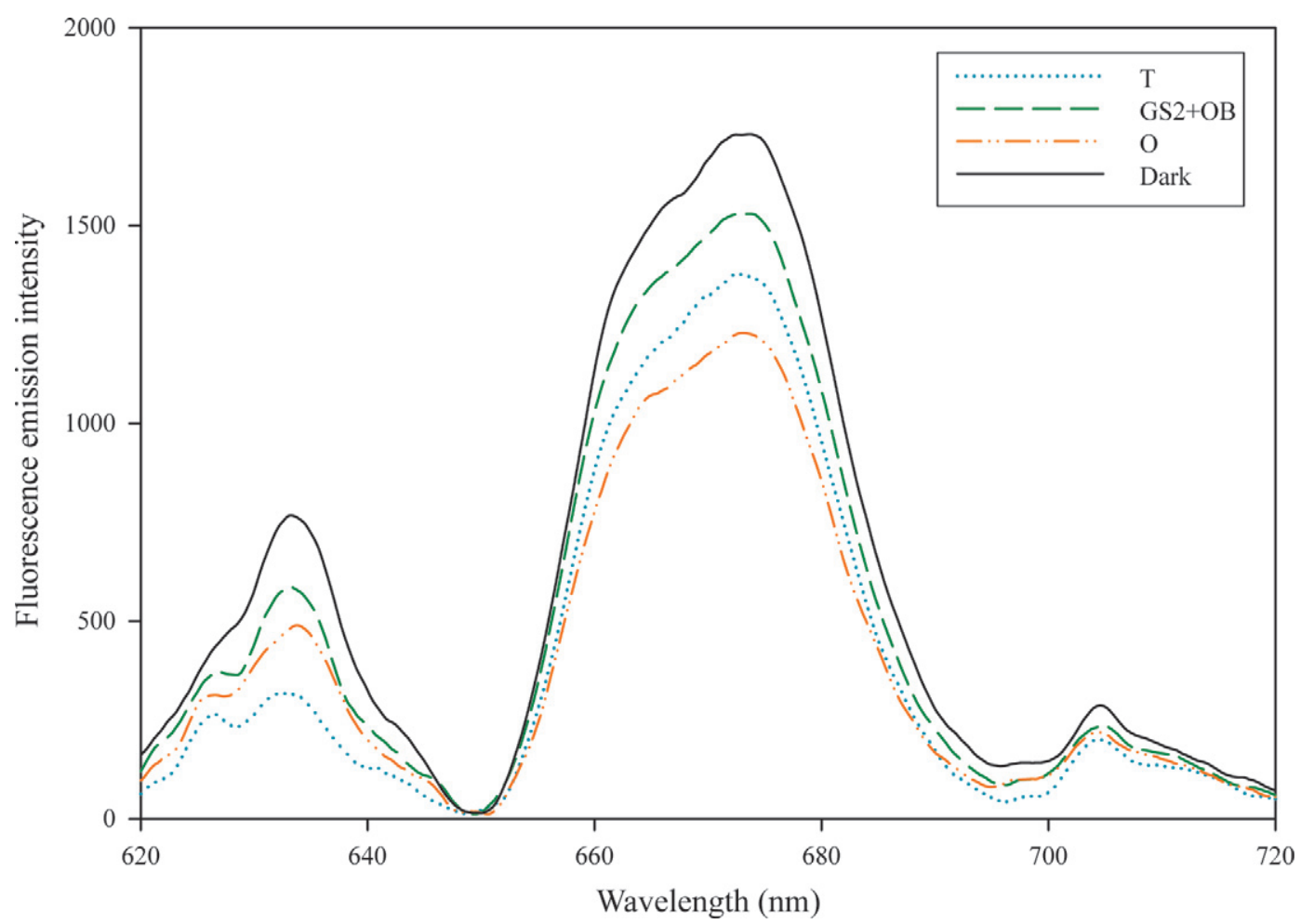

Figure 8. The baseline-corrected fluorescence emission spectra [excitation wavelength $(\lambda \mathrm{ex})=410 \mathrm{~nm}$ ] obtained from milk stored under 3 different colored films: film with a high concentration of green pigment, silver additive, and optical brightener (GS2+OB); non-colored transparent film (T); and orange film (O). Samples were exposed to light under a metal halide lamp for $32 \mathrm{~h}$. The reference sample was milk stored in the dark. Color version available in the online PDF.

regions by tailor-made packaging can be a relevant approach to minimize photooxidation with low-cost films. The approach can also be used for other light-sensitive products. However, it is important to know the photosensitive properties of the products.

\section{ACKNOWLEDGMENTS}

The authors thank Per Lea (Nofima AS, Ås, Norway) for statistical support in sensory evaluation. We are grateful to Hans Sundell, Aud Espadal, Karin Solgaard, Anne Segtnan, Jannike Olavesen, and Frank Lundby (all from Nofima AS) for skillful technical assistance. We acknowledge Diego Airado-Rodríguez (Nofima AS) for fruitful discussions. The Agricultural Food Research Foundation (Oslo, Norway) is greatly appreciated for funding this research.

\section{REFERENCES}

Airado-Rodríguez, D., N. Intawiwat, J. Skaret, and J. P. Wold. 2011. Effect of naturally occurring tetrapyrroles on photooxidation in cow's milk. J. Agric. Food Chem. 59:3905-3914.

Bekbölet, M. 1990. Light effects on food. J. Food Prot. 53:430-440.

Bosset, J. O., P. U. Gallmann, and R. Sieber. 1994. Influence of light transmittance of packaging materials on the shelf-life of milk and dairy products - A review. Pages 223-268 in Food Packaging and Preservation. M. Mathlouthi, ed. Blackie, London, UK.

Cladman, W., S. Scheffer, N. Goodrich, and M. W. Griffiths. 1998. Shelf-life of milk packaged in plastic containers with and without treatment to reduce light transmission. Int. Dairy J. 8:629-636.

Hansen, A. P., T. L. Tuner, and W. L. Aurand. 1975. Fluorescent light-activated flavor in milk. J. Milk Food Technol. 38:388-392.

He, S. T., S. S. Xie, J. N. Yao, H. J. Gao, and S. J. Pang. 2002. Selfassembled two-dimensional superlattice of $\mathrm{Au}-\mathrm{Ag}$ alloy nanocrystals. Appl. Phys. Lett. 81:150-152.

Intawiwat, N., A. V. Dahl, M. K. Pettersen, J. Skaret, E. O. Rukke, and J. P. Wold. 2011. Effect of different wavelength of light on the formation of photo-oxidation in Gouda-like cheese. Int. Dairy J. $21: 531-539$.

Intawiwat, N., E. Myhre, H. Øysæd, S. H. Jamtvedt, and M. K. Pettersen. 2012. Packaging materials with tailor made light transmission properties for food protection. Polymer Eng. Sci. 52:20152024 .

Intawiwat, N., M. K. Pettersen, E. O. Rukke, M. A. Meier, G. Vogt, A. V. Dahl, J. Skaret, D. Keller, and J. P. Wold. 2010. Effect of different colored filters on photooxidation in pasteurized milk. J. Dairy Sci. 93:1372-1382.

ISO (International Organization for Standardization). 1985. Sensory analysis methodology-Flavour profile methods. International Standard 6564. ISO, Geneva, Switzerland.

ISO (International Organization for Standardization). 2009. Milk and milk products - Sensory analysis - Part 2: Recommended methods for sensory evaluation. International Standard 22935-2. ISO, Geneva, Switzerland.

Josephson, D. V. 1946. Some observations regarding the effect of various wavelengths of light on the riboflavin content and flavor of milk. J. Dairy Sci. 29:508-510. (Abstr.) 
Juzenas, P., V. Iani, S. Bagdonas, R. Rotomskis, and J. Moan. 2001. Fluorescence spectroscopy of normal mouse skin exposed to 5-aminolaevulinic acid and red light. J. Photochem. Photobiol. B 61:78-86.

Lieber, C. A., and A. Mahadevan-Jansen. 2003. Automated method for subtraction of fluorescence from biological Raman spectra. Appl. Spectrosc. 57:1363-1367.

Merzlyak, M. N., S. I. Pogosyan, L. Lekhimena, T. V. Zhigalova, I. F. Khozina, Z. Cohen, and S. S. Khrushchev. 1996. Spectral characterization of photooxidation products formed in chlorophyll solutions and upon photodamage to the cyanobacterium Anabaena variabilis. Russ. J. Plant Physiol. 43:160-168.

Mortensen, G., G. Bertelsen, B. K. Mortensen, and H. Stapelfeldt. 2004. Light-induced changes in packaged cheeses - A review. Int. Dairy J. 14:85-102.

Qin, J., and R. Lu. 2007. Measurement of the absorption and scattering properties of turbid liquid foods using hyperspectral imaging. Appl. Spectrosc. 61:388-396.

Sattar, A., J. M. deMan, and J. C. Alexander. 1977. Light-induced degradation of vitamins I. kinetic studies on riboflavin decomposition in solution. Can. Inst. Food Sci. Technol. J. 10:61-64.

Webster, J. B., S. E. Duncan, J. E. Marcy, and S. F. O'Keefe. 2009. Controlling light oxidation flavor in milk by blocking riboflavin excitation wavelengths by interference. J. Food Sci. 74:S390-S398.
Webster, J. B., S. E. Duncan, J. E. Marcy, and S. F. O'Keefe. 2011. Effect of narrow wavelength bands of light on the production of volatile and aroma-active compounds in ultra high temperature treated milk. Int. Dairy J. 21:305-311.

Wold, J. P., R. Bro, A. Veberg, F. Lundby, A. N. Nilsen, and J. Moan. 2006a. Active photosensitizers in butter detected by fluorescence spectroscopy and multivariate curve resolution. J. Agric. Food Chem. 54:10197-10204.

Wold, J. P., K. Jorgensen, and F. Lundby. 2002. Nondestructive measurement of light-induced oxidation in dairy products by fluorescence spectroscopy and imaging. J. Dairy Sci. 85:1693-1704.

Wold, J. P., A. Veberg, F. Lundby, A. N. Nilsen, and J. Moan. 2006b. Influence of storage time and color of light on photooxidation in cheese: A study based on sensory analysis and fluorescence spectroscopy. Int. Dairy J. 16:1218-1226.

Wold, J. P., A. Veberg, A. Nilsen, V. Iani, P. Juzenas, and J. Moan. 2005. The role of naturally occurring chlorophyll and porphyrins in light-induced oxidation of dairy products. A study based on fluorescence spectroscopy and sensory analysis. Int. Dairy J. $15: 343-353$ 